\title{
METALENGUAJE Y METAORGANIZACIÓN EN LA LINGÜÍSTICA SISTÉMICO-FUNCIONAL
}

\author{
Juan Antonio González de \\ Requena Farré
}

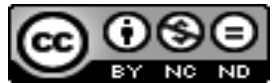

Esta obra está bajo una licencia Creative Commons

Reconocimiento-No Comercial-Sin Obra Derivada 



\title{
METALENGUAJE Y METAORGANIZACIÓN EN LA LINGÜÍSTICA SISTÉMICO-FUNCIONAL
}

\author{
METALANGUAGE AND META-ORGANIZATION IN SYSTEMIC \\ FUNCTIONAL LINGUISTICS
}

\author{
Juan Antonio González de Requena Farré
}

\begin{abstract}
RESUMEN
Este artículo pretende llevar a cabo una revisión teórica de la problemática del metalenguaje en la lingüística sistémico-funcional y propone una reducción funcional de la terminología metalingüística presente en la ciencia del lenguaje contemporánea. Desde una perspectiva sistémico-funcional, el lenguaje aparece como un sistema metaorganizado en virtud de ciertas dimensiones metafuncionales (ideacional, interpersonal y textual) y de una estratificación de planos de realización (semántico-discursiva, léxico-gramatical y fonológica-grafológica) basada en relaciones de metarredundancia. En ese sentido, se exploran las opciones de reducir los rendimientos metalingüísticos, metacomunicactivos y metadiscursivos a la gramática constitutiva del lenguaje natural, sin que sea precisa la escisión recursiva de un metalenguaje formalizado de orden superior o de algún metacódigo acotado.

Palabras clave: metalenguaje, metadiscurso, metacomunicación, metaorganización, lingüística
\end{abstract} sistémico-funcional.

\begin{abstract}
This article aims to carry out a theoretical review of the problem of metalanguage in systemic functional linguistics and proposes a functional reduction of the metalinguistic terminology present in the contemporary science of language. From a functional systemic perspective, language appears as a metaorganized system by virtue of certain metafunctional dimensions (ideational, interpersonal and textual) and a stratification of levels of realization (semantic-discursive, lexicalgrammatical and phonological-graphological) based on relationships of metarredundance. In this sense, the options of reducing metallinguistic, metacommunicative and metadiscursive yields to the constitutive grammar of natural language are explored, without the need for a recursive detachment of a formalized metalanguage of higher order or of some specific metacode.

Key words: metalanguage, metadiscourse, metacommunication, metaorganization, systemic functional linguistics.
\end{abstract}

Dr. Juan Antonio González de Requena Farré. Español. Doctor en Filosofía por la Universidad Complutense de Madrid (UCM), Máster en Lingüística por Universidad Nacional de Educación a Distancia (UNED). Profesor asociado, Universidad Austral de Chile.

Correo electrónico: jgonzalez@spm.uach.cl

Recepción: 08- 03- 2017

Aceptación: 08- 05- 2017 


\section{Introducción}

En la ciencia del lenguaje, la noción lógico-linguiística de metalenguaje adopta un enfoque particular ante la reflexividad del lenguaje, en virtud del cual se apuesta por una perspectiva epistemológica de segundo orden, que permita dar cuenta del lenguaje natural mediante un lenguaje o semiótica de nivel superior, sin incurrir en paradojas de autorreferencia (Hjelmslev, 1971; Tarski, 2005). Por su parte, las concepciones semiótico-funcionales de la función metalingüística privilegian los recursos cotidianos que tenemos para resolver las dificultades y malentendidos en el proceso comunicativo, y atribuyen a los interlocutores la capacidad epistémica de problematizar el código y glosar las expresiones lingüísticas (Jakobson, 1988; Weinrich, 1981). La lingüística inspirada en Coseriu (1981) ha intentado rescatar el saber del hablante y las formas de cultura linguiística implícitas que se hacen presentes en el empleo cotidiano del lenguaje; en ese sentido, cabe diferenciar el metalenguaje genérico (los casos de automención linguiística o los usos metalingüísticos en que se hace referencia al lenguaje), la metalengua (el repertorio de recursos idiomáticos que designan aspectos del lenguaje) y el metadiscurso (las enunciaciones que expresan un saber individual o colectivamente cristalizado sobre el lenguaje) (González-Ruiz y Loureda-Lamas, 2005; Loureda, 2009).

Por otro lado, los enfoques pragmáticos o el análisis de discurso —en la medida en que consideran dimensiones supraoracionales del lenguaje ligadas al proceso comunicativo y a la relación entre los interlocutores - han incorporado una perspectiva diferente sobre la reflexividad linguística, que pone en primer plano las formas de marcado metadiscursivo y de enmarcado metacomunicativo, en virtud de las cuales se organiza el proceso textual, se introducen posicionamientos de los interlocutores y se negocian estratégicamente los significados y relaciones intersubjetivas (Hyland, 2005; Lucy, 1993; Silverstein, 1993; Stubbs, 1987). En cuanto a los estudios literarios, el problema de la reflexividad metalinguiística se ha vinculado a las formas de trascendencia transtextual que atraviesan productivamente el texto poético; en ese sentido, resultan cruciales las modalidades de invocación polifónica de los discursos referidos, la citación intertextual o el comentario metatextual (Genette, 1989).

Como se puede apreciar, en la ciencia del lenguaje contemporánea se despliega un complejo arco de posibles perspectivas de la reflexividad metalinguíística, y esta diferencia de enfoques sobre el metalenguaje se traduce en una notable dispersión de los usos del vocabulario metalingüístico. En este trabajo, se exploran las opciones de reducir los rendimientos metalingüísticos, metacomunicactivos y metadiscursivos a la gramática constitutiva del lenguaje natural, de acuerdo con una perspectiva sistémico-funcional. Además, compartimos las reservas de Halliday (2002a, 2003a) respecto a la posibilidad de disponer de metalenguajes formalizados de orden superior para hablar de la intrincada gramática tácita inherente al lenguaje cotidiano.

\section{La desconfianza del metalenguaje}

Al reflexionar sobre las ideas que nos hacemos del lenguaje, Michael A. K. Halliday (2003a) manifestaba cierta desconfianza respecto a aquellos metalenguajes teóricos que se sitúan al margen de nuestra experiencia de la creación cotidiana de significado. Al fin y al cabo, los primeros términos lingüísticos que utilizamos en nuestra infancia no son categorías gramaticales (como nombre, verbo, palabra u oración, por ejemplo), sino verbos que remiten 
a los actos de significación y a acciones simbólicas (como decir o contar), e incluso se pueden reportar actos de significación sin verbos explícitos como decir. Según Halliday, cuando un niño comienza a hablar, ya dispone de una considerable conciencia tácita de las funciones del lenguaje, y puede empezar a hablar sobre el lenguaje, al mismo tiempo que lo emplea, tanto en la acción como en la reflexión, para pensar sobre el mundo, estructurar su experiencia, expresar su personalidad e interactuar con el mundo y con los otros. Ya en nuestra infancia, elaboramos cierta lingüística espontánea que nos permite distinguir algunos aspectos de los actos de significación, como el decir, el nombrar o el significar; pero, con la escolarización, esas ideas sobre el lenguaje como recurso potencial para pensar y actuar son reemplazadas por las categorías y reglas de la gramática escolar, con su codificación explícita. En fin, en nuestra reflexión lingüística espontánea podemos reconocer la coexistencia de una concepción del lenguaje como recurso semiótico, asociada a nuestra socialización primaria, y de una concepción del lenguaje como repertorio de reglas, que es parte de la realidad secundaria del conocimiento organizado y la instrucción escolar oficial (Halliday, 2003a, pp. 92-95).

Según Halliday (2003a), también la historia de la lingüística refleja el desplazamiento desde una comprensión del lenguaje como recurso retórico, hasta una concepción del lenguaje que privilegia las reglas, el valor de verdad de los juicios y, en definitiva, la estructura lógica. En ese sentido, podemos rastrear hasta los orígenes de la reflexión gramatical en Grecia cierta escisión entre la concepción de la estructura gramatical como configuración de funciones inherentes al lenguaje y, por otra parte, el aislamiento de constituyentes que representarían funciones lógicas; se trata de un corte, que llega hasta la actualidad, entre una lingüística descriptiva etnográfica de los recursos semióticos y una lingüística filosófica de las reglas lógicas. La visión lógico-filosófica del lenguaje subordina la lingüística a la filosofía, y la gramática a la lógica; desde Aristóteles, pasando por la Escolástica y Port-Royal, hasta Chomsky, sostiene un punto de vista prescriptivo, normativo e idealizado, centrado en el significado como valor de verdad, y representa el lenguaje como una estructura intelectual regida por reglas y analizable formalmente (al punto de considerar ideal el lenguaje lógico artificialmente formalizado). La concepción descriptivo-etnográfica privilegia las variaciones y anomalías, así como el significado en tanto que función retórica; desde los sofistas, hasta Whorf, la sociolingüística y los actuales enfoques funcionalistas, representa el lenguaje como un recurso semiótico en que está en juego la actividad y la selección de opciones, así como privilegia la interpretación semántica del discurso, la variación lingüística y los usos concretos del lenguaje en situaciones específicas. Según Halliday, en la historia de las ideas lingüísticas habría sucedido lo mismo que en el desarrollo individual: la realidad secundaria y reestructurada en virtud del conocimiento organizado desplaza a la concepción primaria del lenguaje como recurso; de hecho, los defensores de la tradición formal lógico-filosófica del lenguaje consagran la idealización del lenguaje como inventario universal de reglas, en la misma medida en que rechazan la concepción funcional del lenguaje como recurso semiótico (Halliday, 2003a, pp. 95-112). No obstante, Halliday considera que en la cultura contemporánea se ha abierto camino una concepción semiótica de la cultura como potencial de significado o como sistema de significaciones que se realiza de muy diferentes modos y con distintas funciones, de manera que los recursos simbólicos de la cultura permiten a las personas descubrir, crear e intercambiar significados. Desde esta perspectiva semiótica, resulta posible concebir el lenguaje como uno de los sistemas semióticos que conforman la cultura, con la particularidad de que el sistema semiótico del lenguaje puede contribuir a la realización 
de otros sistemas semióticos, llevar a cabo la construcción de la realidad social, entender la variedad de los lenguajes humanos e, incluso, hablar sobre el propio lenguaje (Halliday, 2003a, pp. 113-115).

Para Halliday (2003b), la evolución humana se ha desplegado como cierta conversación, de la cual ha emergido una semiótica específicamente humana y una forma distintiva de diálogo basado en el sistema del lenguaje. A través de la actividad semiótica del lenguaje, no solo nos comunicamos y construimos las realidades en las cuales actuamos y vivimos, sino que, además, forjamos el orden social y el orden natural que nos cobijan. Esta construcción dialógica de la realidad social y del orden natural a través de la lengua natural es interactiva y presupone nuestro hablar recíproco, así como la traducción de todo tipo de informaciones al lenguaje natural y nuestra interpretación de los órdenes de la naturaleza y la sociedad, mediante la generalización y la abstracción lingüística. Ahora bien, —según Halliday- esta deriva evolutiva de nuestro lenguaje habría dado paso a la irrupción de nuevas formas de diálogo en aquellos contextos culturales en que el lenguaje se torna escrito: aparecen nuevos modos semióticos que redefinen nuestro diálogo con el orden social y natural; asimismo, a partir de los lenguajes naturales, se desarrollan distintos metalenguajes (como los de la matemática o las ciencias) que, no obstante, conservan un vínculo con el lenguaje natural en que resultan interpretados. El lenguaje humano constituye genéricamente un sistema dinámico abierto que, como semiótica social, aporta los recursos y el potencial de significación para pensar y actuar; pero las presiones derivadas del crecimiento y organización del conocimiento científico y tecnológico inducen la irrupción de metalenguajes, esto es, lenguajes diseñados para organizar y forjar las nuevas formas de conocimiento. Cabría pensar que esta emergencia de metalenguajes torna problemático el funcionamiento del lenguaje y altera el diálogo con el entorno, en la medida en que los metalenguajes basados en el lenguaje natural son rígidos, categóricos e incapaces de dar cuenta de la fluidez dinámica de la experiencia o de las múltiples relaciones complementarias en el orden socio-natural (Halliday, 2003b, pp. 116-123).

No obstante, frente a las quejas de los científicos respecto a la rigidez del lenguaje natural y ante las quejas de los lógicos relativas a la imprecisión del lenguaje cotidiano, Halliday (2003b) defiende que el lenguaje natural es precisamente dinámico, interactivo y fluido, de manera que cuenta con los recursos semióticos que le permiten hacerse cargo de nuestro diálogo con el entorno. No en vano, el lenguaje natural cotidiano con que hablamos espontáneamente es capaz de recoger las diferentes perspectivas complementarias de la realidad; puede construir nuestro orden social y natural, sin necesidad de hacer referencia explícita al sistema constructivo o a los patrones gramaticales implícitos que dan forma inadvertidamente a cierto orden de la realidad. Según Halliday, en sus rasgos gramaticales ocultos, los lenguajes naturales ordinarios esbozan interpretaciones complejas del orden natural y, al constituir semióticas multifuncionales, logran significar varios asuntos al mismo tiempo, como la acción y la reflexión, la interpretación y la modificación de nuestras realidades. En ese sentido, la estructura de la cláusula organiza los significados y representa la realidad como un flujo de acontecimientos; los sistemas de proyección permiten construir los acontecimientos de la experiencia como eventos semióticos mediante procesos de conciencia (como ocurre en el discurso referido); la expansión establece relaciones lógico-semióticas entre acontecimientos; la transitividad da forma a los procesos de la experiencia, ya sean externos, internos o atribuidos, bajo las formas complementarias de la transmisión o de la causación; el tiempo y el aspecto introducen ciertas modelizaciones complementarias de la temporalidad, 
bien como decurso lineal (pasado, presente, futuro), bien como relación simultánea (entre ser y llegar a ser, la manifestación y lo manifestado). Halliday concibe una bifurcación estilística en nuestros modos semióticos de construir el orden natural, que presenta dos polos complementarios (entre los cuales cabe situar diferentes opciones semióticas). Por una parte, la construcción del mundo como un inventario de cosas y como un cuadro sinóptico estático, tal como ocurre en los lenguajes emergentes del conocimiento científico, con su alto grado de densidad léxica, con su complejidad estructural y con las taxonomías conceptuales que lo caracterizan. Por otra parte, un modo semiótico dinámico (filogenéticamente anterior), que modeliza la realidad como un flujo de acontecimientos en devenir, a través del lenguaje cotidiano y de su intrincada gramática tácita, así como patentiza las interrelaciones de los procesos en los contextos humanos dialógicos. (Halliday, 2003b, pp. 128-134).

La sospecha de Halliday acerca de los metalenguajes radica en los efectos que tiene la reflexión consciente sobre la capacidad constructiva tácitamente realizada a través de la gramática del lenguaje ordinario: con la reflexión consciente, el lenguaje se torna algo extraño y se transforma en un repertorio determinado y cerrado de categorías provistas unilateralmente por algún metalenguaje específico. De ese modo, cuando la gramática tácita del lenguaje natural se transforma en un metalenguaje dirigido al razonamiento lógico explícito, se privilegia unilateralmente la descripción categórica y se pierde la capacidad automatizada de construcción de realidades. La dificultad para hacer explícita la gramática tácita del sistema semiótico de la lengua natural radica en que depende de la opción de hablar sobre la propia gramática inherente de la lengua, a través de alguna teoría gramatical, esto es, mediante algún metalenguaje científico diseñado, en el cual los términos gramaticales se conforman como categorías rígidas y reificadas (Halliday, 2003b, pp. 122-125). Halliday considera que el lenguaje natural no solo constituye una teoría de la experiencia, sino que es parte de la experiencia, de manera que el sistema socio-semiótico del lenguaje puede incluirse a sí mismo en sus descripciones y autorreferirse. De ese modo, la gramática puede dar lugar a una teoría de la gramática, y la reflexividad se hace presente en nuestra praxis lingüística y en nuestra práctica como lingüistas. Ahora bien, Halliday privilegia el habla cotidiana y el discurso dialógico natural, que no está auto-supervisado gramaticalmente; se trata de un modo semiótico que exhibe espontáneamente su condición de sistema dinámico abierto y construye interactivamente nuestros órdenes sociales y naturales, mediante una intrincada gramática tácita con escasa densidad léxica y pocas metáforas gramaticales. En fin, más que multiplicar los metalenguajes especializados, debemos aprender a pensar gramaticalmente a través de la construcción gramatical tácita y de los modos semióticos construidos en el propio lenguaje natural (Halliday, 2003b, pp. 135-137).

Desde la perspectiva de Halliday (2002a), los metalenguajes que la lingüística diseña parcialmente para hacerse cargo del propio lenguaje (en virtud de un giro reflexivo del lenguaje sobre sí mismo) topan con el problema de la inefabilidad de la intrincada gramática tácita con la cual construimos nuestros órdenes sociales y naturales. En la terminología lingüística se da la particularidad de que, desde tiempos de los griegos, los términos técnicos se han desarrollado a partir del lenguaje natural cotidiano y de su lingüística espontánea, para posteriormente tomar distancia del empleo cotidiano, en la medida en que se forjaban teorías y se fijaba una nomenclatura gramatical técnica. Una vez consumada la reificación de categorías abstractas como instancias dadas, la teoría gramatical se habría preguntado por la definición de su significado y la decodificación de su contenido y valor, de una manera tan circular como 
tautológica, en la medida en que no se distingue la categoría de su interpretación (por ejemplo, se define el nombre como aquello que nombra una cosa). En ese sentido, - para Halliday-gran parte de la terminología lingüística parece afectada por un desdoblamiento de significado, puesto que un mismo término abstracto reificado se refiere tanto a una unidad de significado como a una unidad léxico-gramatical (Halliday, 2002a, pp. 291-297).

En el caso de los metalenguajes de la lingüística, topamos con que el lenguaje es su propio metalenguaje, de manera que el significado de las categorías gramaticales no se puede glosar sino en el lenguaje natural y, por tanto, resulta inefable. En efecto, —-según Hallidaylos lenguajes naturales no parecen muy adecuados para glosar con ellos los propios hechos del lenguaje, ya que nuestro vocabulario metalinguiístico permanece enmarcado en la gramática inherente a la propia lengua natural. Desde esa perspectiva, resulta problemático emplear el lenguaje natural como metalenguaje, pues sus sistemas ideacional y lógico no han sido diseñados explícitamente para cumplir esa labor; pero, además, hay una dificultad adicional vinculada a la autorreferencia de un metalenguaje que coincide con el mismo sistema semiótico que se describe. Sin embargo, - para Halliday - el problema de fondo no consiste tanto en que no se pueda glosar con el lenguaje natural, sino en el hecho de que el lenguaje no puede ser glosado adecuadamente, ya que su intrincada gramática tácita no consiste en un inventario de categorías con significados explicitables, sino que solo se realiza como funciones gramaticales arbitrarias y no motivadas semánticamente. Por eso, no podemos glosar correctamente el significado de categorías gramaticales como sujeto, tópico, tema, definido, pasiva, etc. Por más que se pretenda que las glosas de las categorías gramaticales aportan generalizaciones semánticas vinculadas a alguna semiótica de orden superior, Halliday considera que las categorías gramaticales permanecen inefables, pues conciernen a aquellas formas tácitas (criptotipos como la transitividad o el sistema del género) que escapan a la conciencia del hablante del lenguaje, aunque subyacen a la construcción semiótica de sus realidades naturales y sociales. En fin, nuestra capacidad de emplear el lenguaje cotidiano solo se despliega si no somos conscientes de hacerlo; nuestra posibilidad de significar solo se cumple si no atendemos al proceso del significado. El lenguaje natural presupone una intrincada gramática que le permite desplegar su dinamismo creativo, pero no podemos tomar conciencia de esta complejidad inherente de otra manera que a través de los limitados medios léxicos del lenguaje que se ha tornado consciente. La paradoja que plantean las categorías gramaticales consiste - según Halliday - en que subyacen a nuestra representación de la experiencia y la modelan, pero no pueden representarse conscientemente ni ser parafraseadas o glosadas en un lenguaje transparente ajeno a las categorías gramaticales. A diferencia de los metalenguajes científicos diseñados específicamente para lograr explicitud y efabilidad del conocimiento, el lenguaje natural constituye un sistema evolucionado que presupone una intrincada gramática tácita, y sus principios no pueden explicitarse mediante la categorización consciente. Desde esa perspectiva, la gramática tácita del lenguaje natural exhibe una riqueza constructiva para dar cuenta de toda nuestra experiencia cultural, y asimismo sitúa sus categorías más allá del alcance de nuestra interpretación consciente. Resulta más razonable, pues, preguntarse por los paradigmas semánticos que se realizan en determinado registro del lenguaje, en vez de pretender explicitar el significado de las formas gramaticales; es más factible adquirir conciencia de las categorías gramaticales al relacionarlas con el contexto cultural, el contexto situacional y el texto, que pretender definir explícitamente el significado de las formas gramaticales (Halliday, 2002a, pp. 297-311). 


\section{Metafunciones y metarredundancia en el lenguaje natural}

En la redescripción metafórica que Halliday formula del lenguaje natural, se asume que una realidad socio-cultural consiste en un edificio de significados o en una construcción semiótica, uno de cuyos sistemas de creación de significado primordiales es el lenguaje. Según Halliday (1982a), el lenguaje es una semiótica social en la medida en que el lenguaje se interpreta dentro de un contexto socio-cultural, y la cultura se interpreta en términos semióticos. En ese sentido, la construcción de la realidad social resulta inseparable del sistema semántico del lenguaje y de su potencial de significado compartido. Desde la perspectiva de una semiótica social, encontramos una relación sistemática entre los contextos sociales de instanciación del significado y los componentes semántico-funcionales mediante los cuales se realizan típicamente (en tanto que los componentes funcionales son activados por los elementos situacionales): el campo (el tipo de acción o proceso social), en el componente que permite representar la experiencia; el tenor (la relación social y el reparto de roles), en el componente interpersonal de la comunicación; el modo u organización simbólica, en el componente textual. De esa manera, - según Halliday- el sistema linguiístico se organiza de modo tal que se pueden predecir las opciones de significación a partir de los elementos situacionales, o el texto desde el contexto. En última instancia, la variación socio-lingüística es inseparable de las opciones del sistema lingüístico, así como el sistema lingüístico es un producto del sistema social. En ese sentido, el lenguaje no ha de ser considerado como un sistema de reglas, sino como un recurso de significación o potencial de significado, que dispone opciones y requiere elecciones en contextos socio-culturales (Halliday, 1982a, pp. 245-249).

En este marco sociosemiótico, Halliday lleva a cabo una reconstrucción del sistema de significación del lenguaje, que enfatiza la presencia de algunas metadimensiones organizadoras del proceso de creación de significado: las metafunciones y la metarredundancia. En virtud de la presencia de metafunciones y de metarredundancia, el sistema de significación del lenguaje natural se perfila como una semiótica metaorganizada, cuya gramática tácita da forma a mucho más que la simple relación referencial entre expresión y contenido. Por una parte, el sistema lingüístico es socialmente funcional y constituye un recurso o potencial de significación; cumple distintas funciones en la actividad social y está organizado en componentes funcionales y modos de significación, de manera que usar el lenguaje involucra optar en el entorno de otras opciones y en el marco de ciertos componentes funcionales generales. Según Halliday, ya el protolenguaje infantil está motivado funcionalmente y constituye un medio para alcanzar fines socialmente relevantes. El potencial de significado de los primeros recursos verbales del niño responde a un abanico de funciones primarias: la función instrumental de obtención de bienes y servicios que satisfacen sus necesidades materiales; la función reguladora, que le permite influir en el comportamiento ajeno; la función interactiva, para involucrar a otras personas; la función personal de automanifestación e identificación de sí mismo; la función heurística, para explorar el mundo externo e interno; la función imaginativa, que permite forjar ficcionalmente un mundo propio; o bien la función informativa, que permite comunicar reportes. Con la adquisición del lenguaje adulto, el concepto de función experimenta una radical transformación, en la medida en que deja de designar los usos concretos ligados a la acción o la reflexión verbales aisladas; se dispone - según Halliday - como un conjunto de metafunciones interdependientes, y remite a la expresión simbólica generalizada y abstracta, que reorganiza todo el repertorio de funciones semánticas del lenguaje en un solo espacio 
semiótico multifuncional y en un paradigma sistemático. Como sistema de significación de orden superior, el lenguaje adulto comprende una metafunción ideacional (esto es, la función del lenguaje como reflexión de un mundo de experiencia y de relaciones lógicas), una metafunción interpersonal (o sea el lenguaje como acción y negociación de las relaciones sociales) y una metafunción textual (es decir, el manejo de la textura de los mensajes y del flujo de la información). Estos componentes funcionales aportan recursos y un potencial de significado solo relativamente independiente de las opciones seleccionadas en los otros componentes, y se realizan léxico-gramaticalmente (Halliday, 1982b, pp. 30-34).

Por otra parte, la lingüística sistémico-funcional presupone que el lenguaje es un sistema estratificado de recursos lingüísticos (fonológicos, léxico-gramaticales y semánticodiscursivos), cada uno de los cuales contribuye a la construcción del significado, y aporta jerárquicamente esos recursos para la realización de las metafunciones básicas del lenguaje, a saber: la ideación del entorno socio-natural, la interacción social y la organización textual de los mensajes. Formalmente, el sistema de codificación del lenguaje exhibe una estratificación en tres niveles: contenido, forma y expresión; o, en otros términos, el plano semántico del discurso, el sistema léxico-gramatical y el plano fonológico. Halliday observa que los componentes semánticos se realizan típicamente en algún tipo de estructura gramatical: el componente experiencial, en la composición de los constituyentes (por ejemplo, en el estrato léxico-gramatical, los morfemas, las palabras, los grupos, las cláusulas); el componente lógico, en construcciones recursivas; el componente interpersonal, en la prosodia; el componente textual, en las estructuras que garantizan la cohesión y organización temática (Halliday, 1982a, pp. 241-245). En ese sentido, además de exhibir una organización en componentes metafuncionales, el lenguaje natural adulto resulta organizado de modo estratificado en virtud de un principio de metarredundancia. Halliday toma el concepto de Jay Lemke, quien caracteriza la metarredundancia en términos de la jerarquía de relaciones de contextualización que pueden darse en un sistema de significación, haciendo predecibles ciertas conexiones en la construcción del significado. Por ejemplo, la expresión facial puede resultar redundante respecto de las palabras que la acompañan, de manera que se puede establecer la probabilidad de la expresión facial a partir de las palabras, y viceversa. Pero, además, la combinación redundante de expresiones faciales y verbales puede resultar metarredundante en relación a las situaciones en que típicamente se contextualizan esas expresiones. A su vez, el sistema metarredundante de las expresiones faciales, las palabras y las situaciones puede ser metametarredundante respecto a los mundos simbólicos en que suele contextualizarse ese sistema. E, incluso, puede ocurrir que todo el sistema de relaciones contextuales conformado por las expresiones faciales y verbales, las situaciones y los mundos sostenga una relación de metarredundancia respecto al sistema de significación opcionalmente desplegado por una comunidad humana. Desde la perspectiva de Lemke, estas relaciones de contextualización que sustentan la relación de metarredundancia son relaciones de significado; de ese modo, cabe concluir que todo significado es relacional, y que la descripción de todas las operaciones de contextualización realizadas por una comunidad nos entrega la descripción completa de su sistema de significación (Lemke, 1995, pp. 143147). Desde la perspectiva de Halliday (2002b), la metarredundancia se da en la medida en que, en un sistema estratificado, ciertas expresiones $(a, b, c)$ realizan una forma $(1, \mathrm{~m}, \mathrm{n})$, que a su vez es una realización de los significados (, , q, r), de manera que la conexión redundante entre expresión y forma establece una relación de metarredundancia con el significado. En la adquisición del lenguaje, la redundancia biplanar de la expresión y el contenido da paso a 
esta metarredundancia compleja, de manera que las relaciones de contextualización se tornan iterativas, y puede darse eventualmente una recontextualización metarredundante de las relaciones metarredundantes entre expresión, forma y significado, a través de un nivel superior como el contexto de situación o, incluso, del género discursivo. En fin, la metarredundancia nos permite formalizar el principio de estratificación que marca a los sistemas de significación del lenguaje, y da cuenta de la realización de unos estratos en otros por medio de relaciones de contextualización, así como permite predecir las probabilidades contextuales de realización de cada variación sistemática (Halliday, 2002b, pp. 355-359).

La metaorganización del sistema semiótico del lenguaje natural, mediante metafunciones y a través de la estratificación metarredundante, hace posible que en la gramática tácita del lenguaje cotidiano se produzcan realineaciones de las relaciones entre los distintos estratos (semántico-discursivo, léxico-gramatical y fonológico) y las distintas funciones (ideacional, interpersonal y textual) que conforman su sistema de significación. En efecto, dada esta metaorganización estratificada y funcional del lenguaje, cabe concebir numerosas formas de metáfora gramatical, en las cuales tiene lugar cierta reconstrucción y realineamiento proyectivo entre los estratos semántico-discursivo y léxico-gramatical. Según Halliday (Halliday y Matthiessen, 2004), existe metáfora gramatical cuando las representaciones semánticas y sus elementos (entidades participantes, procesos, circunstancias y relaciones) no se realizan congruentemente en la estructura oracional y en los grupos verbales o nominales que figuran en las oraciones. Las metáforas gramaticales pueden ser ideacionales, si se reconstruye léxico-gramaticalmente la representación semántico-discursiva, y se da un desplazamiento de un tipo de función semántica a otra mediante un desplazamiento entre clases gramaticales. Por ejemplo, la representación semántica de un proceso desarrollado por una entidad participante se realiza congruentemente en una cláusula con un grupo nominal y un grupo verbal (como Los soldados disparan); pero también puede realizarse en el estrato léxico-gramatical como un grupo nominal, de manera que el proceso aparezca como una cosa o estado de cosas (como ocurre en la nominalización Los disparos de los soldados) (Halliday y Matthiessen, 2004, pp. 636-642). Halliday también contempla la existencia de otro tipo de metáforas gramaticales, las metáforas interpersonales, que extienden el potencial del sistema semántico intersubjetivo, haciendo posible disponer de más recursos para ejercer roles sociales y negociar los patrones de relación social. Concretamente, las metáforas interpersonales constituyen formas de realización léxico-gramatical incongruente, como sucede al reconstruir las apreciaciones mediante proyecciones evaluativas, o bien al reorientar las actitudes implicadas mediante la modalización de las proposiciones o la modulación de las propuestas. Es lo que ocurre cuando una evaluación no se realiza a través de adverbios y epítetos (Obraste incorrectamente, o Tu comportamiento fue indecente), sino mediante una cláusula que matiza la proposición como opinión personal (Creo que no hiciste lo debido); o lo que pasa cuando se realiza una orden (;Cállate!) como una petición o afirmación (¿Podrías callarte? o A veces, conviene callarse), de manera que se reubica la responsabilidad. En ese sentido, las metáforas interpersonales juegan con lo explícito e implícito de las orientaciones subjetivas y objetivas en la realización léxico-gramatical, incrementando así las estrategias de negociación en el trato social (Halliday y Matthiessen, 2004, pp. 613-621). En fin, la metáfora gramatical constituye una manifestación de la metaorganización del sistema de significación del lenguaje natural, que posibilita la reorganización cotidiana de su potencial semiótico. 
La lingüística sistémico-funcional de Halliday caracteriza el sistema de significación del lenguaje como un sistema abierto en que tiene lugar la selección de opciones en el contexto de otras opciones. De ese modo, se introduce una concepción del sistema linguiístico que no coincide con caracterizaciones anteriores del sistema de la lengua como sistema cerrado de signos sujetos a relaciones estructurales de oposición diferencial, o bien como sistema comunicacional autorregulado en que los enunciados del hablante anticipan las respuestas del oyente y se retroalimentan con ellas. Aunque Halliday no se refiere explícitamente a un tipo de sistema metaorganizado, aporta caracterizaciones decisivas de los componentes metafuncionales, de las relaciones de metarredundancia y de las opciones de realineación semiótica mediante la metáfora gramatical, de manera que parece congruente conceptualizar como un sistema metaorganizado - en el sentido de un trans-sistema o de un sistema transorganizado - la intrincada gramática tácita del sistema de significación del lenguaje. En síntesis, las principales características de este tipo de sistema metaorganizado, cuyo principal paradigma es el lenguaje humano cotidiano (y no algún código informacional, algún algoritmo computacional, los servomecanismos o los organismos biológicos), desbordan las propiedades de los sistemas cerrados, de los sistemas abiertos, de los sistemas autorregulados e, incluso, de los sistemas autoorganizados y autopoiéticos (como las entidades biológicas). En el sistema metaorganizado del lenguaje, los subsistemas y recursos semióticos del sistema son multifuncionales y desarrollan (meta)funciones generalizadas e interdependientes; además, los subsistemas y recursos semióticos están sujetos a relaciones jerárquicas de contextualización y realización en otros estratos (metarredundancia); finalmente, las relaciones entre componentes y funciones semióticas están sujetas a realineación opcional (metáfora gramatical).

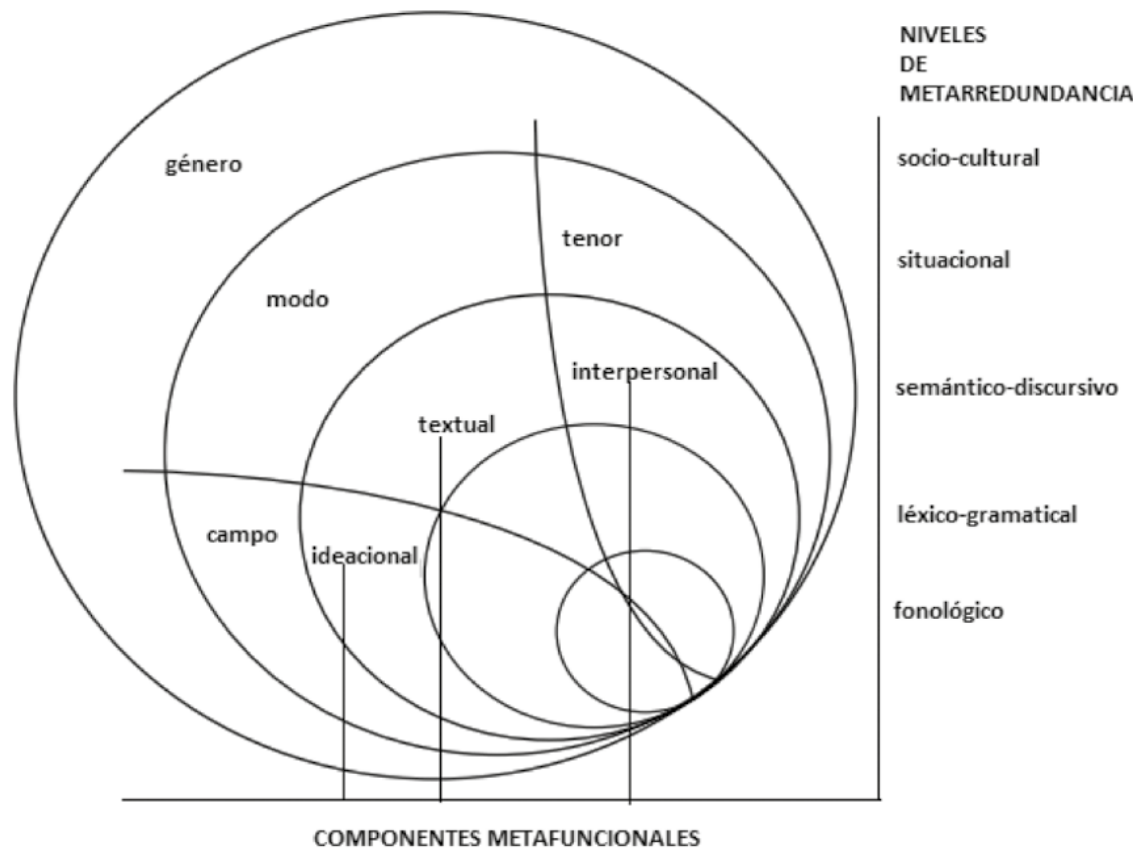

Figura 1. Componentes metafuncionales y relaciones de metarredundancia en el sistema metaorganizado de significación del lenguaje natural. Adaptación de Martin (2011, p. 103) 


\section{Una reducción funcional del metalenguaje}

Al considerar que el sistema de significación del lenguaje natural está sistémicamente metaorganizado (en virtud de la presencia de dimensiones metafuncionales y de la jerarquización de relaciones de metarredundancia), una concepción sistémico-funcional como la de Halliday disipa en gran medida la especulación acerca de la existencia de un metalenguaje separado del lenguaje objeto. Si toda expresión del lenguaje cotidiano puede resultar multifuncional (al cumplir simultáneamente metafunciones ideacionales, interpersonales y textuales), y si todo estrato del lenguaje natural puede ser recontextualizado en virtud de relaciones de metarredundancia, entonces se vuelve problemática la distinción entre un metalenguaje que solo habla formalmente del lenguaje y, por otra parte, un lenguaje objeto que representa referencialmente el mundo. Cabría afirmar, pues, que la posibilidad de operar metalingüísticamente está inscrita de modo inherente en la gramática tácita del lenguaje natural, puesto que toda expresión del lenguaje natural cotidiano involucra recontextualizaciones metarredundantes y desempeña metafunciones relacionadas con la negociación interpersonal del significado o la organización textual de la información, y no solo con la representación de la experiencia. Por eso, tal vez resulte preferible hablar de una metaorganización del lenguaje natural, en vez de hipostasiar un metalenguaje escindido. En fin, si asumimos el argumento precedente y reconocemos que no hay un metalenguaje formalmente escindido ni funciones metalingüísticas especiales, entonces cabría redescribir la mayoría de los fenómenos considerados metalingüísticos, en términos de los sistemas de significación del lenguaje natural cotidiano.

Desde esa perspectiva, la posibilidad de que se hable de los procesos del habla no supone un extraño desdoblamiento metalingüístico del lenguaje. Aparece inscrita en la semántica del discurso, pues se trataría un tipo de proceso representable en la estructura de la cláusula (que se realiza léxico-gramaticalmente a través de todo un repertorio de verbos relativos al decir), o bien estaríamos ante un tipo de relación lógico-semántica realizada en cláusulas complejas, la proyección, en la cual una cláusula del decir se vincula a otra cláusula dependiente, que representa el contenido lingüístico bajo la forma de una locución, ya sea citada directamente o reportada indirectamente (por ejemplo, Juan dijo “ibasta ya!”; o Juan dijo que bastaba ya). En ese sentido, la proyección lógico-semántica no solo permite reproducir la expresión, sino también representar la expresión verbal como un contenido dicho (Halliday y Matthiessen, 2004, pp. 440-466). Por lo demás, la proyección lógico-semántica no concierne únicamente a la metafunción ideacional, o sea, a la posibilidad de representar relaciones lógico-semánticas entre el decir y lo dicho, o a la reconstrucción semiótica de la experiencia del proceso de decir. Y es que la proyección también se asocia a la metafunción interpersonal del lenguaje natural, esto es, a distintos modos de negociar interpersonalmente el significado, mediante movimientos estratégicos como la formulación de propuestas discutibles o proposiciones fácticas, o bien a través de esa forma de lenguaje evaluativo que consiste en comprometerse en cierto modo con la enunciación, al atribuir lo dicho a fuentes e introducir otras voces discursivas, mediante la cita o el reporte de lo dicho. En ese sentido, la proyección del decir forma parte tanto de la dimensión lógico-semántica del discurso cuanto del sistema del lenguaje evaluativo, al aportar un recurso para que el hablante o escritor se posicione ante el valor del enunciado y ante las posibles respuestas a la posición valorativa expresada. No en vano, al representar una proposición como si se fundase en la subjetividad de una voz externa, 
la enunciación heteroglósica de la proposición aparece como una posición negociable, que invoca otras alternativas dialógicas (como ocurre en Los conservadores dicen que la política está en crisis, en vez de La política está en crisis). En fin, la atribución de lo dicho a alguna fuente externa implica cierta posición valorativa que puede consistir tanto en el reconocimiento de la validez de la fuente como en el distanciamiento respecto a la voz de ese otro enunciador; de ese modo, se alinean estratégicamente las relaciones entre los interlocutores (Martin y Rose, 2007, pp. 49-52; Martin y White, 2005, pp. 114-117). Además de vincularse con el ámbito lógico-semántico del discurso y con la evaluación interpersonal, la proyección del decir mediante citas de las expresiones o reportes del significado se realiza en el sistema gráfico de la organización textual, a través de signos de puntuación marcadores de estatus, como las comillas (Halliday, 1989, pp. 34-35).

Del mismo modo que la posibilidad de hablar del hablar o la mención de lo dicho están inscritas transversalmente en la gramática tácita del lenguaje cotidiano y no involucran un metalenguaje desdoblado, la glosa de los términos también constituye un recurso inherente de nuestro lenguaje y no una función lingüística especial. En el ámbito de la semántica del discurso, no solo se da la opción de construir semióticamente la experiencia como procesos entre participantes: las cláusulas relacionales tienen la posibilidad de representar los procesos como el ser de entidades y hechos; pueden construir y modelar la experiencia como vínculos generalizados de membrecía e identidad. La identificación llevada a cabo en algunas cláusulas relacionales implica generalmente la asignación de una identidad, de manera que una cosa se identifica por medio de otra. De hecho, la glosa es una de las opciones que nos brindan las cláusulas relacionales para formular relaciones abstractas de identificación entre un valor semiótico y una instancia. Por ejemplo, una cláusula relacional como Quietud significa que nada se mueve establece una relación de identificación entre una palabra y el significado que esta realiza; se trata de una opción basada en la gramática tácita del sistema semiótico, que permite modelar la relación de realización entre dos estratos, bajo la forma de cláusulas relacionales de identidad. En el caso de la glosa terminológica, las cláusulas de identificación juegan un papel decisivo en la construcción del conocimiento, pues representan una estrategia para la expansión de los recursos de designación del lenguaje, y pueden suministrar definiciones de diccionario. Dentro del repertorio de cláusulas relacionales de identificación (que comprende, entre otras, las cláusulas de equivalencia, de designación, de definición, de ejemplificación o de demostración), la glosa y la traducción realizan un tipo de identificación basado en la simbolización; de modo análogo, el nombrar o el definir constituyen ejercicios lingüísticos en que se identifica la instancia de una palabra con el valor de su significado. Por ejemplo, la cláusula relacional "Híbrido" es una criatura procreada por individuos de distintas especies encierra una operación lingüística de nominación o definición entre una instancia y un valor semiótico, más que un salto lógico a algún metalenguaje (Halliday y Matthiessen, 2004, pp. 227-239).

En el caso de la terminología técnica o científica que figura en algún registro especializado, la glosa puede tener lugar a través de estrategias de destilación del significado, como la elaboración de un grupo nominal (por ejemplo, "Metarredundancia": la idea de patrones de un nivel semiótico que redundan con los patrones del nivel siguiente), y puede ir acompañada de diagramas que den cuenta del término de un modo multisemiótico. Como se puede apreciar, ni siquiera la glosa de terminología especializada implica la intervención de un metalenguaje formalmente escindido, sino que se realiza genéricamente a partir de cierto 
tipo de expansión lógico-semántica. En concreto, la glosa consiste en relaciones de elaboración semiótica (como la ejemplificación, la reformulación o la identificación), que se manifiestan a través del sistema del contenido de un lenguaje, tanto en la semántica de los textos como en la dimensión léxico-gramatical de las palabras. Por ejemplo, la definición de un término técnico puede representarse como una cláusula relacional de identificación en que el término a definir figura como instancia, y la glosa del término, como el valor definicional identificador que se realiza mediante grupos nominales con una estructura extendida. En ese sentido, las definiciones suelen introducir los términos de los glosarios o diccionarios, y pueden darse elaboraciones adicionales de la definición nuclear a través de distintas estructuras retóricosemánticas. Por lo demás, las definiciones de términos técnicos no solo se realizan a través de los recursos del texto científico, sino que además pueden registrarse en géneros discursivos diferentes, como los del diccionario (centrado en la información léxico-gramatical) o el tesauro (que privilegia las relaciones léxico-semánticas). De ese modo, la definición y glosa del significado constituyen recursos discursivos realizados en el contexto de géneros de discurso determinados, pero no implican la presencia de un metalenguaje formal separado (Matthiessen, Teruya y Lam, 2010, pp. 23-28).

No solo la noción de metalenguaje parece problemática cuando nos tomamos en serio la metaorganización inherente al lenguaje natural; también la noción de metadiscurso resulta prescindible en un enfoque como el sistémico-funcional. Ciertamente, la concepción del lenguaje de Halliday podría constituir un marco teórico relevante para dar cuenta de las formas de posicionamiento textual, personal e interpersonal en la comunicación. Al fin y al cabo, en la perspectiva sistémico-funcional se asume que la metafunción ideacional (que nos permite representar y reconstruir la experiencia) se realiza conjuntamente con la metafunción interpersonal (la negociación del significado, el posicionamiento ante los otros y la expresión evaluativa) y la metafunción textual (el empleo del lenguaje al servicio de la organización coherente y cohesionada del propio texto). Desde ese punto de vista, el significado de un texto presupone la integración de las tres metafunciones, de manera que cada una de ellas se entiende por relación con las otras. No obstante, la noción de metadiscurso no se encuentra en la terminología de Halliday, quizá debido al enfoque comprehensivo del sistema de significación del lenguaje, que caracteriza a la lingüística sistémico-funcional. En efecto, los posicionamientos discursivos, la negociación del significado, la expresión de actitudes y el lenguaje evaluativo constituyen elementos de la semántica del discurso que se realizan léxicogramaticalmente en el modo, en los marcadores de modalidad y polaridad, en las expresiones actitudinales (como los epítetos), en el sistema personal (pronombres y determinantes posesivos) o en la deixis; fonológicamente, se despliegan en los rasgos prosódicos y en el tono, y, gráficamente, a través de marcadores de estatus y de relación aportados por signos de puntuación que indican el acto de habla (como los signos de interrogación y exclamación), o permiten expresar digresiones (como los guiones largos). Por su parte, el significado textual se realiza a través de la estructura textual completa, que determina el orden de aparición de los elementos y los patrones de organización informativa; pero también involucra las relaciones de conjunción, elaboración y expansión semióticas, así como las formas de referencia y correferencia, la coherencia léxica o sistemas como los de la sustitución y la elipsis, e incluso concierne al estrato gráfico de la realización textual (como se evidencia en la puntuación o el diseño) (Halliday y Matthiessen, 2004, pp. 328-329). En fin, cabría pensar que el sistema de significados del lenguaje realiza de modo conjunto las tres metafunciones del lenguaje, 
sin que pueda aislarse un inventario discreto de marcadores metadiscursivos que servirían exclusivamente para posicionarse argumentativamente o dar organización y coherencia estructural al texto. En ese sentido, Halliday nos invita a concebir el discurso como un proceso interactivo en que se crean simultáneamente el contenido proposicional, el compromiso interpersonal y el flujo del propio texto; por el contrario, ciertas teorizaciones del metadiscurso parecen asumir que se pueden separar las expresiones de contenido proposicional y, por otra parte, algunos rasgos textuales aislados o marcadores discursivos específicos, que encarnarían de modo exclusivo los aspectos interpersonales y las indicaciones de la organización textual (Hyland, 2005, pp. 26-27).

Por razones análogas a las que hemos empleado para cuestionar la pertinencia de los conceptos de metalenguaje y de metadiscurso en la gramática sistémico-funcional, se podría argumentar que el término metacomunicación resulta innecesario en una concepción del lenguaje que asume que todo enunciado involucra una negociación interpersonal del significado. Desde la perspectiva de Halliday, hay todo un sistema del intercambio dialógico, en el cual pueden llevarse a cabo distintos movimientos discursivos de iniciación y respuesta, así como diferentes actos de habla (la afirmación, la pregunta, la orden o la oferta). Cuando el lenguaje se emplea para intercambiar información, la cláusula asume la función semántica de una proposición, pero si está en juego el intercambio de bienes y servicios, la función semántica de la cláusula se realiza como una propuesta (Halliday y Matthiessen, 2004, pp. 106-111). Como ocurría con el metadiscurso, cabría pensar que el sistema de significación del lenguaje no dispone de un código de recursos discretos que agoten el significado metacomunicativo (esto es, las formas de negociación del significado y el curso del intercambio dialógico), como algo diferenciable del contenido proposicional. Los lenguajes no desarrollan recursos especiales de metacomunicación para dirigir la conducta del interlocutor o formular ofertas en el curso del diálogo. Sin embargo, el sistema de significación del lenguaje involucra recursos semióticos transversales para la realización conjunta del contenido proposicional, las propuestas interpersonales y la organización textual, que se pueden poner al servicio de diferentes funciones y movimientos retóricos en el intercambio comunicativo. Los patrones de negociación del significado y las pautas de evaluación discursivas no se deciden desde un plano metacomunicativo separado; resultan contextualizados en virtud de relaciones de metarredundancia con el contexto de situación, específicamente con el tenor interpersonal del registro (los roles institucionales, las relaciones de poder, la distancia social o el afecto) e, incluso, con el contexto socio-semiótico aportado por cierto género de discurso que realiza una ideología determinada y se realiza a su vez en algún registro discursivo. En fin, más que con una metacomunicación formalmente separable, nos encontramos con la capacidad de metaorganización del sistema de significación inherente al lenguaje natural cotidiano, en tanto que proceso socio-semiótico sujeto a la relación metarredundante con los contextos socio-culturales. De esa manera, la organización semánticofuncional simboliza la estructura de la interacción social, al tiempo que los recursos semióticos del lenguaje pueden simbolizar y reconstruir simbólicamente la estructura de la sociedad y de la cultura (Halliday, 1982a, pp. 244-248).

\section{Conclusión}

Una aproximación sistémico-funcional aporta una visión comprehensiva de los recursos semióticos del lenguaje natural, en virtud de la cual se podrían organizar adecuadamente y distribuir orgánicamente los muy distintos fenómenos designados como metalingüísticos. 
Podríamos considerar que lo que tradicionalmente se ha designado como metalenguaje corresponde a las formas de reflexividad representacional, proyección experiencial y recursividad lógica, que son inherentes al componente ideacional del lenguaje. En ese sentido, la distinción entre metalenguaje del discurso y metalenguaje de la lengua tan solo expresaría los diferentes estratos de realización de la reflexividad ideacional: el metalenguaje del discurso correspondería al estrato semántico-discursivo en que se proyectan enunciados y se elaboran relaciones enunciativas (en el contexto de cierto campo discursivo y de algún género de discurso); el metalenguaje de la lengua se inscribiría en el estrato léxico-gramatical en que se realiza la semántica del discurso, mediante las unidades léxicas y la gramática tácita de una lengua natural. Por otra parte, el término metacomunicación concierne al componente interpersonal del sistema de significación del lenguaje, en la medida en que designa las formas de negociación de los significados, los posicionamientos enunciativos y evaluaciones de la enunciación, así como el control de las relaciones comunicativas. También en el caso de la metacomunicación, cabría pensar que existe una metacomunicación del discurso, consistente en las propuestas semántico-discursivas sistemáticamente realizadas en el contexto de cierto tenor del discurso y en el marco socio-cultural de ciertos géneros discursivos; asimismo, habría una metacomunicación de la lengua, esto es, el estrato correspondiente a los recursos léxico-gramaticales que realizan los significados interpersonales (como el modo, la modalidad o la prosodia). Por último, lo que se ha designado como metadiscurso cubriría parcialmente las formas de organización reflexiva del proceso textual, a través de la gestión estratégica de la información y del manejo reflexivo de la coherencia referencial y la cohesión textual; y es que, en la bibliografía reciente, el concepto de metadiscurso suele emplearse para designar tanto la relación interpersonal de los interlocutores y los posicionamientos discursivos cuanto las formas de organización reflexiva del texto. Quizá sería pertinente designar como metatexto a estas formas de organización reflexiva de la información, de la coherencia referencial y de la cohesión textual; ahora bien, el concepto de metatexto ha sido utilizado en teoría literaria para nombrar cierto tipo de relación transtextual como la ejercida a través del comentario implícito o la crítica (o sea, lo que otros enfoques considerarían metadiscurso). En todo caso, podría reconocerse un metadiscurso o metatextualidad del discurso, esto es, el estrato de la realización semántico-discursiva de la organización textual en cierto modo discursivo y género de discurso; así como cabría hablar de un metadiscurso o metatextualidad de la lengua, consistente en todos aquellos recursos del estrato léxico-gramatical que permiten realizar el proceso textual de forma organizada, coherente y cohesionada (como la estructura informativa, el sistema de la conjunción y los marcadores discursivos).

Desde una perspectiva sistémico-funcional resulta más fácil concebir el nexo entre el lenguaje natural y la construcción semiótica metalingüística, ya que podemos preguntarnos por los contextos de realización de la reflexividad metalingüística más allá de la cláusula. Se abre así la posibilidad de indagar los contextos de realización que hacen predecibles ciertas estructuras metarrepresentacionales de la semántica del discurso, tal y como se realizan en un campo determinado (por ejemplo, las definiciones disciplinares o las glosas terminológicas); pero también cabe preguntarse por los patrones de negociación del significado característicos de cierto tenor metacomunicativo (como la regulación y control de la asimetría comunicativa), o bien explorar las pautas de organización metatextual que son propias de algún modo de estructuración textual (más o menos dialógica, por ejemplo). En fin, en un enfoque sistémicofuncional la reflexividad metalingüística no se ejerce mediante un metalenguaje formalmente 
escindido, sino a través de todo el sistema de significación del lenguaje natural, con sus distintos componentes metafuncionales y estratos: solo así cabe concebir adecuadamente la construcción sociosemiótica de la propia reflexión lingüística y los contextos y marcos socioculturales en que tiene lugar la realización de la actividad metalingüística.

Quizá el aporte más interesante de un enfoque sistémico-funcional radica en la desconfianza respecto al metalenguaje como instrumento formal de explicitación de la gramática tácita del lenguaje natural. En este trabajo, hemos compartido la sospecha de que la reflexividad del lenguaje atraviesa todo el sistema de significación del lenguaje natural, pero no puede formalizarse explícitamente la intrincada gramática tácita que nos permite comunicarnos cotidianamente. No resulta necesario situarse en un plano metalingüístico, metacomunicativo o metadiscursivo - formalmente separados - , para entender que el sistema de significación del lenguaje natural cuenta con recursos para proyectar la enunciación, glosar los términos, negociar los significados, posicionar a los interlocutores, organizar la información o preservar la coherencia y cohesión textuales. El enfoque sistémico-funcional nos permite describir algunas formas de metaorganización del lenguaje natural que conforman la intrincada gramática tácita de la comunicación cotidiana, aunque no pueda formalizar explícitamente las categorías universales de nuestra gramática. Aporta una redescripción del sistema de significación del lenguaje en que la representación de contenidos proposicionales está siempre ligada a las relaciones interpersonales de los interlocutores y a la organización del texto; además, da cuenta de las relaciones de metarredundancia que subyacen a los estratos del sistema del lenguaje, incluidos los contextos situacionales y los marcos socio-culturales que seleccionan sistemáticamente ciertos recursos expresivos. De esa manera, la lingüística sistémico-funcional rompe con el espejismo epistemológico de que existe una perspectiva de segundo orden escindida y un plano de metalenguaje formalmente separado, desde los cuales se puede agotar la reflexión metalingüística sobre los recursos del lenguaje. Asimismo, se impugna la ilusión "epistemocéntrica" (Bourdieu, 1999, pp. 72-76) de que solo es posible la reflexión metalingüística si se ejerce desde la perspectiva desapegada y universalista del teórico del lenguaje (aunque en algunas versiones de esa ilusión todos llevaríamos un metalingüista dentro, con un cabal conocimiento intuitivo de las reglas universales del lenguaje). En fin, la hipostasia de la reflexividad metalingüística, como si se tratase de un código de orden superior o de una perspectiva de segundo orden, corresponde a una ilusión epistemológica y epistemocéntrica que sobrestima el lugar del saber experto y del especialista disciplinar, en el sistema de significación del lenguaje. Precisamente, el enfoque sistémico-funcional nos permite concebir desde los mismos recursos semióticos del lenguaje natural cotidiano cómo se despliega la construcción sociosemiótica del saber del lenguaje y la distribución de la competencia lingüística; o bien de qué manera se estructura el reparto socio-cultural de los registros y géneros discursivos que posibilitan la reflexividad del lenguaje, la inscripción de la voz ajena, el distanciamiento de la enunciación o la referencia intertextual.

\section{Bibliografía}

Bourdieu, P. (1999). Meditaciones pascalianas. (T. Kauf, tr.). Barcelona: Anagrama.

Coseriu, E. (1981). Principios de semántica estructural. (M. Martínez-Hernández, tr.). (2 ed.). Madrid: Gredos. 
Genette, G. (1989). Palimpsestos. (C. Fernández-Prieto, tr.). Madrid: Taurus.

González-Ruiz, R., y Loureda-Lamas, O. (2005). Algunos estudios recientes sobre lo metalingüístico en español. Verba. 32, 351-369.

Halliday, M. A. K. (1982a). Una interpretación de la relación funcional entre el lenguaje y la estructura social. El lenguaje como semiótica social. (237-249). (J. Ferreiro-Santana, tr.). México D. F.: Fondo de Cultura Económica.

Halliday, M. A. K. (1982b). El lenguaje y el hombre social (parte 1). El lenguaje como semiótica social. (17-51). (J. Ferreiro-Santana, tr.). México D. F.: Fondo de Cultura Económica.

Halliday, M. A. K. (1989). Spoken and written language. (2 ed.). Oxford: Oxford University Press.

Halliday, M. A. K. (2002a). On the ineffability of grammatical categories. On Grammar. Volume 1 in the Collected Works of M. A. K. Halliday. (92-115). London: Continuum.

Halliday, M. A. K. (2002b). How do you mean? On Grammar. Volume 1 in the Collected Works of M. A. K. Halliday. (352-368). London: Continuum.

Halliday, M. A. K. (2003a). Ideas about language. On Language and Linguistics. Volume 3 in the Collected Works of M. A. K. Halliday. (92-115). London: Continuum.

Halliday, M. A. K. (2003b). Language and the order of nature. On Language and Linguistics. Volume 3 in the Collected Works of M. A. K. Halliday. (116-138). London: Continuum.

Halliday, M. A. K. y Matthiessen, C. M. (2004). An Introduction to Functional Grammar. (3 ed.). London: Hodder Arnold.

Hjelmslev, L. (1971). Prolegómenos a una teoría del lenguaje. (J. L. Díaz de Liaño, tr.). Madrid: Gredos.

Hyland, K. (2005). Metadiscourse. Exploring Interaction in Writing. London: Continuum.

Jakobson, R. (1988). El metalenguaje como problema lingüístico. El marco del lenguaje. (8191). (T. Segovia, tr.). México, D. F.: Fondo de Cultura Económica.

Lemke, J. L. (1995). Textual Politics. Discourse and Social Dynamics. London: Taylor \& Francis.

Loureda, O. (2009). De la función metalingüística al metalenguaje: Los estudios sobre el metalenguaje en la lingüística actual. Revista Signos. 42 (71), 317-332.

Lucy, J. A. (1993). Reflexive language and the human disciplines. Por J. A. Lucy (Ed.). Reflexive language. Reported speech and metapragmatics. (9-32). Cambridge: Cambridge University Press.

Martin, J. R. (2011). Systemic Functional Linguistics. Por K. Hyland y B. Paltridge (Eds.). Continuum Companion to Discourse Analysis. (101-119). London: Continuum.

Martin, J. R. y Rose, D. (2007). Working with discourse: meaning beyond the clause. (2 ed.). London: Continuum.

Martin, J. R. y White, P. R. R. (2005). The language of evaluation: appraisal in English. New York: Palgrave Macmillan.

Matthiessen, C. M. I. M., Teruya, K. y Lam, M. (2010). Key Terms in Systemic Functional Linguistics. London: Continuum. 
Silverstein, M. (1993). Metapragmatic discourse and metapragmatic function. Por J. A. Lucy (Ed.). Reflexive language. Reported speech and metapragmatics. (33-58). Cambridge: Cambridge University Press.

Stubbs, M. (1987). Análisis del discurso. Análisis sociolingüístico del lenguaje natural. (C. González, tr.). Madrid: Alianza Editorial.

Tarski, A. (2005). La concepción semántica de la verdad y los fundamentos de la semántica. Por L. M. Valdés-Villanueva (Ed.). La búsqueda del significado. Lecturas de filosofía del lenguaje. (299-335). (4 ed.). Madrid: Tecnos.

Weinrich, H. (1981). De la cotidianidad del metalenguaje. Lenguaje en textos. (110-139). Madrid: Gredos. 